\title{
CL 246738
}

National Cancer Institute

\section{Source}

National Cancer Institute. CL 246738. NCI Thesaurus. Code C1052.

An immunomodulator, 3,6-bis(2-piperidinoethoxy) acridine trihydrochloride, used in a phase I study for possible immunostimulatory effects in colorectal cancer. ( $\mathrm{NCl})$ 